Derecho \& Realidad

Núm. 24 • Il semestre de 2014

Facultad de Derecho y Ciencias Sociales, UPTC

ISSN: 1692-3936

\title{
Instrucción de litigantes, de Antonio de Paz Y Salgado: un modelo alternativo desjudicializador de los conflictos*
}

Litigants Instruction, of Antonio de Paz y Salgado: an alternative non-judicial model to resolve conflicts

\author{
Rafael Antonio López Murcia**
}

\section{Resumen}

Interesante exploración histórica que revela como en un recientemente descubierto texto del siglo XVII, ya se hablaba de "desjudicializar" los conflictos, por medio de la amigable composición. Los sabios consejos en tan antiguas calendas, dejan entrever una gran sabiduría que nos recuerda el adagio popular: "es mejor un mal arreglo, que un buen pleito". El autor es actualmente juez en Tegucigalpa.

\section{Palabras clave}

Justicia, Honduras, amigable composición, historia del derecho.

* Este artículo fue publicado en el diario Tiempo, de San Pedro Sula, Honduras, los días 26 y 27 de diciembre de 2005. Reimpreso en el número 37 de Caxa Real, Boletín Histórico-Literario de la UNAH correspondiente al mes de febrero de 2006.

** Abogado y especialista en Derechos Humanos, Universidad Nacional Autónoma de Honduras (UNAH). 
Derecho y Realidad

\begin{abstract}
This is an interesting historical exploration that reveals how a recently discovered text of the seventeenth century already talked of "non-judicial methods" to resolve conflicts, through amicable settlement. The wise advice in such ancient times shows a great wisdom that reminds us the popular adage: "Better a bad deal, than a good lawsuit". The author is currently a judge in Tegucigalpa.
\end{abstract}

\title{
Keywords
}

Justice, Honduras, amicable settlement, history of law. 
":Y por qué motivo vive el hombre si no es por la justicia, que es perfección, la perfección que es santidad, la santidad que es amor?"

(Edilberto Cardona Bulnes, "Zarpa y poesía, o los extraterrestres”)

Es poco lo que sabe sobre Antonio de Paz y Salgado, jurista que vivió en el siglo XVIII en el "Reyno de Guathemala", jurisdicción de lo que actualmente se conoce como Centroamérica. El investigador guatemalteco Jorge Luján Muñoz es posiblemente el único historiador contemporáneo que nos ha brindado una reseña de su obra. En su obra Un jurista y autor ignorado del Reino de Guatemala: D. Antonio de Paz y Salgado (1981), lo pondera uno de los pocos autores que escribieron durante la época colonial en Centroamérica, y lo considera digno de ser "descubierto" o rescatado del olvido. Era natural, según su expediente de graduación en la Universidad de San Carlos de Guatemala, “... del Real de Minas de Tegucigalpa (hoy capital de Honduras)" (1981, p. 6). Se desconoce, en cambio, la fecha de su nacimiento.

Creemos que un gran impulso en ese sentido de rescate histórico fue dado por el licenciado Octavio Rubén Sánchez Barrientos, quien encontró y fotocopió el original del libro Instrucción de litigantes, o guía para seguir pleitos, en la biblioteca de la Universidad de Harvard, Estados Unidos de América. En dicha copia se lee con claridad que la obra fue hecha "Con licencia en Guathemala, en la imprenta de Sebastián de Arebalo: año de 1742". En tal sentido, se trata de la misma edición que tuvo a la vista el historiador citado; aunque el ejemplar que él tuvo a la vista proviene de la Biblioteca Nacional de Chile, Colecctio Medinencis (No. 6752) (Luján, 1981, p. 8).

Luján Muñoz (1981) describe así la obra:

Tiene siete hojas iniciales o preliminares (dedicatoria, aprobación, licencias, y prologo) y se divide en dos partes, la primera con treinta hojas y la segunda con veinticuatro hojas, en ambos casos sin foliar (...) Cuando leí el título... pensé que se trataba de un formulario procesal. Sin embargo, su primera parte está dirigida a profanos en el derecho que estén pensando en iniciar un pleito en el fuero. Y el consejo fundamental que contiene es evitar litigios.

Esto da una fuerte noción de la importancia del texto, pues en la tradición bibliográfica hondureña, los antecedentes de autores hondureños -o nacidos en 
Honduras- conocidos se remonta hasta el siglo XIX. Un factor importante en ello, lo constituye el reconocimiento oficial de que la primera imprenta vino al país en el año de 1830, traída por el general Francisco Morazán, siendo su primera publicación el diario La Gaceta.

La bibliografía del autor oriundo del Real de Minas no es, sin embargo, completamente desconocida. A juzgar por el ensayo de Luján Muñoz, ya a finales del siglo XIX, Ramón A. Salazar, director de la Biblioteca Nacional de Guatemala dice de él que “... su labor merece ser mejor conocida y divulgada, quizá no tanto por su calidad, como por lo inusitado que resultan sus obras. Se trata de un caso singular, que se movió en géneros literarios poco cultivados en Guatemala durante la colonia: el humorismo y la obra jurídica” (1981).

El Dr. Renzo Honores, mientras tanto, nos ofrece un punto de vista moderno que mucho y bien habla de la valía del libro comentado. En El uso de las probanzas de testigos en los litigios sobre curacazgos ante la Real Audiencia de Lima, 15501610 (s.f.) cita como autoridades en el derecho procesal de la época (siglo XVII), a Alonso de Villadiego y Juan de Hevia Bolaños y agrega: “... En las Indias la situación era en muchos aspectos análoga y estos libros obtuvieron mucho predicamento entre los miembros de la profesión legal hasta la aparición de libros nativos, como los de Antonio de Paz y Salgado con su célebre Instrucción de litigantes, o guía para seguir pleitos (Luján, 1981)". (La negrilla no está en el original).

Al momento de publicarse la Instrucción, la única casa de estudios superiores en Honduras era el Colegio Tridentino, el cual se fundó a finales del siglo XVII -bajo los auspicios de San Agustín de Hipona- y cuyo histórico edificio se puede apreciar ahora a un costado de la catedral de Comayagua. Su programa de estudios, hasta entrado el siglo XVIII, era más bien magro. Consistía en: “...Gramática, teología moral, canto, música y administración de la época” (Contreras, 2004). En ese entorno cultural, no deja sorprender la aparición de una obra forense y literaria como la Instrucción, la cual se considera hasta cierto punto como sucesora de los prestigios de un Villadiego y de un Hevia Bolaños (autor a su vez de la célebre Curia Philipica, de 1603).

Es de destacar también, que la Instrucción de litigantes puede considerarse como contemporánea de la obra Speculum Iuris (1725), de Gugliemo Duranti, la cual es considerada como “... el antecedente más antiguo, remoto o lejano de nuestra asignatura. La misma abarcaba una síntesis del conocimiento jurídico de la época, y aunque más bien constituía un libro manual o vademécum para uso de los jueces, perseguía también cierto propósito de iniciación en los estudios jurídicos” (Monjarrez, 1998, p. 3). 
Análoga intención se aprecia en la Instrucción de litigantes, pero dirigida a las personas legas en derecho, especialmente aquellas abocadas a los pleitos litigiosos. Se aúna así en esta fructífera obra, una visión jurisprudencial práctica, dotada de una teología moral e incluso de nociones de lógica jurídica, aunque, como es de suponer por el título, también de derecho procesal. En este último sentido, no cabe duda de que la segunda parte del libro cumplía funciones publicistas del proceso judicial inquisitorio, aun y cuando, como nos es dable suponer, esto no constituyese de manera alguna un designio de la "política criminal" de la época.

Se trata de un buen espejo del espíritu de la época, en el cual se entrelaza lo teológico con lo profano, donde la duda cartesiana y el cálculo leibniciano aún no han sentado su autoridad moderna. Pero también puede concebirse como negación de la máxima de experiencia que divide tajantemente el mundo de lo teórico jurídico (deóntico), con el mundo de la práctica, de la vida, que es propia de alguna vertiente del dualismo positivista. En este sentido, nuestro autor reconoce modestamente: “... guiado sólo de mi propia (sic) observación entré a formar esta obrilla...”, mas es obvio también que, aun cuando fuese improbable que Antonio de Paz y Salgado hubiese conocido la obra de Duranti, esto no significa que nuestro autor no fuese un estudioso consumado de las humanidades y un verdadero erudito de lo jurídico. Contribuye a esta apreciación la textura de su trabajo y lo atinado, plural y sorprendente de sus fuentes, las cuales provienen principalmente de los clásicos castellanos y latinos, pero no están desprovistas de expresiones chispeantes en italiano y hasta en portugués.

Puntualmente se viene a la mente la expresión de un José Cecilio del Valle, el ilustrado hondureño del siglo XIX, amigo personal de Jeremy Bentham, quien al referirse en un ensayo a la naturaleza y a los sabios, señala a la profesión de abogado como: “... (es) contraria a las ciencias porque la sucesión rápida de asuntos no permite profundizar en ninguno, porque si se examinan las cuestiones es con interés a favor de los clientes sin la imparcialidad necesaria” (Oquelí, 2004, p. 26-27).

Y lo que vemos aquí es una especie de "espía" u observador desinteresado, que tras una buena parte de su vida dedicada al ejercicio forense, traslada su conocimiento teórico y empírico al saber popular de su siglo, en un lenguaje además inteligible y ameno. Y esto solo en cuanto a la primera parte de su Instrucción, pues es claro que Paz y Salgado también recoge el legado jurídico especializado (La Recopilación de Castilla, sus comentaristas y glosadores, etc.) en la segunda parte de la obra, donde, como bien reseña Luján Muñoz, pretende brindar: "una breve muestra del orden judicial en todas las causas civiles y criminales, comprendiéndose sumariamente los principales y ordinarias formalidades de los procesos" (1981, p. 9).

Sin embargo, es especialmente en las reglas sugeridas a los litigantes en la primera 
parte ("la que contiene algunas reglas de prudencia importantes para la mejor dirección de los negocios"), donde se da a conocer el carácter moderno, anticipatorio y si se quiere alternativo, de su obra jurídica. Son los consejos de un práctico del derecho, en tanto abogado de cortes, y de un estudioso del derecho -y de las fuentes en que abreva el derecho- en un grado cierto. En el prólogo declara fehacientemente: “... pero yo guiado sólo de mi propia (sic) observación entré a formar esta obrilla, y allí no será mucho, que como primera producción, a lo menos para mí en esta línea, tenga muchos errores en las suyas. Si a los genios austeros no les agradase, poco cuidado me da, que yo también suelo no estar para gracias, y como les sirva de algo a los litigantes, veis aquí logrado el fin”.

Un resumen de las reglas contenidas en la primera parte de la obra, dirigidas al litigante avisado, respetando la gramática, ortografía y, especialmente, el espíritu de la época en que las escribió Antonio de Paz y Salgado, puede leerse así:

Regla Primera: Seguir consejos basados en la razón y en la prudencia: “... Tienen la pasión, y el proprio interés cierto genero de tinieblas que derraman en los negocios para oscurecérnoslos, $\mathbf{y}$ jamás he visto juez con acierto en propria causa". (sic)

Regla Segunda: Tener por certísimo el adagio que dice: Más vale mala composición, que buen pleito. "Jamás estos acarrean nada favorable, ni crian buena sangre, de unos en otros vienen encadenados los litigios, de manera, que en exitandose uno, se haze un seminario de discordias". "Para que la rueda de los litigios no corra, han de suspender el agua, han de contener la lengua". (sic)

Regla Tercera: Diligenciar los acuerdos que se logren en "la composición", por escrito; evitando que las mil turbulencias de la pasión empañen la inteligencia de lo acordado.

Regla Cuarta: Buscar ministros íntegros y diligentes. Abogados "buenos para el caso", que sean hombres de bien, "dotados de ciencia y conciencia". Evitar consiguientemente aquellos que: “... por no expeler los pichones del Palomar, como dice el citado Eminentissimo de Luca, traen siempre en la boca aquel maldito proloquio: que no hay causa mala, siendo el Abogado bueno"1. (sic)

\footnotetext{
Resulta interesante contrastar esta cuarta regla con la observación de Morse (1999) en El Espejo de Próspero: Un estudio de la dialéctica del nuevo mundo; ensayo en el cual propone que Pedro Abelardo, ya en la edad media, "... preanuncia dos nociones que son fundamentales para cualquier consideración de la civilización occidental: la de ciencia, que aplica los primeros principios del intelecto al orden teórico, y la de conciencia, que los aplica en el orden práctico... la búsqueda de la certeza objetiva de la prueba y la certidumbre subjetiva de la conciencia se hallarían subyacentes a la integración de la tradición escolástica del siglo XII al XIII, a su subsiguiente desintegración y a los desenlaces "revolucionarios" de los siglos XVI y XVII". (P. 31).
} 
Regla Quinta: Ejercitar con prudente cuidado el ingreso voluntario del litigante a los pleitos, "... a la manera que en un desafío se igualan las armas, y se remueve toda ventaja, pues va mui expuesto á el vencimiento el que lleba inferiores". (sic)

Regla Sexta: Elegido que sea el procurador de la causa -con la prudencia y prevención necesaria- instruirle con verdad y claridad en la presentación del caso, "... para lo que es convenientissimo guardar methodo, y orden”. (sic)

Regla Séptima: Método para brindar exacta y puntual relación o descripción del hecho. El litigante, "aunque sea rudamente, y con sus voces sinceras y estilo poco limado contar su cuento comprendiéndolo bajo de estas circunstancias: Quien sea el que pide, o se oponga lo pedido; Qué sea lo que se pide, o se niega; A quien le pide, o contra quien se excepciona; Por qué se pide, o se niega, Y con que medios se prueba lo uno u lo otro". El objetivo de la regla es enseñar al litigante a informar debidamente la causa, para no dejar todo a cargo de la paciencia de los profesores.

Regla Octava: "Y se reduce a que el litigante ponga su dinero en persona de toda su satisfacción, y confianza, por cuya mano se vaya administrando a los oficiales conforme lo fueran ganando, de cuya prevención estén todos informados y sabedores, para que con eficacia se apliquen a las funciones de su ministerio". Basa este consejo en lo dispuesto en la Ley 12, título 28, libro 2 de la Recopilación de Indias.

Regla Novena: No importunar a los profesores con frecuentes visitas para "repetirles el cuento", pues ello equivale a defraudarles el tiempo, siendo como son, personas ocupadas; “... pues cuando pudiera el Profesor emplearse en ordenar las cosas para el mejor éxito de la causa, les gasta el litigante las horas con inútiles conversaciones, que no producen otra cosa, que una mal recibida molestia".

Regla Décima: También deberá abstenerse el litigante de precisar con instancias a los Ministros, "... por que en vez de ponerles alas les pondrá plomo en los pies". "Todas las cosas se maduran y sazonan con el tiempo, y el misterioso secreto de la prudencia se encierra en saber viar de la coyuntura, por cuyos motivos será bien que, el negociante no quiera apresurar, y con sus fogocidades exponer al peligro su propria causa". (sic)

Regla Undécima: "Ocultar el favor, y la esperanza que se tuviere en la causa, porque no hay cosa mas perniciosa, que el que anden los litigantes echando piernas (como dicen) con el fabor ageno". "En ninguna materia es provechosa 
la jactancia, aun los fabores divinos se deben recatar. No reveló San Pablo los que experimento, todo lo reduxo a reconocidas admiraciones. Siempre merecio el primer lugar entre los prudentes aquel que tiene ojos para ver, juicio para notar, boca para callar y valor para sufrir". (sic)

Regla Duodécima: "En saber pedir consiste toda la felicidad del conseguir". O dicho en una imagen sugestiva de la cultura jurídica de la época: "La brevedad es lisongera (sic), y se gana mas con sus precisiones, que con la mas robusta fuerza de la razon". (sic)

Regla Decimotercia: "Tratar con mucha cortecia, estimacion, y honra a los Juezes, Abogados, y Procuradores, pues lo merecen por sus ejercicios y empleos, si al medico lo hace honorable la necesidad, porque no ha de tener igual efecto lo que exige al el litigante. Es la cortezania, y urbanidad un hechizo politico, y tiene tanta virtud para obligar, que consigue mas un adarme de ella, que quintales de razon". Explica mas adelante, que esta actitud debe de moderarse: "... de manera, que sin pisar la raya de la adulación, y abatimiento, deberá dentro de los terminos de la afabilidad, hazerle lugar a la aceptación". (sic)

Regla Decimoquarta: "Tratar con igual cortecia, y demostraciones a todos los demas oficiales del fuero, aunque sean de infima clase, teniendolos a todos gratos, y obligados, porque ex minimis maxima pendent, y no solamente las cosas grandes impiden, y embarazan el camino...". La posibilidad de una interpretación maliciosa de lo anterior, la trata de evitar Paz y Salgando, echando mano de la siguiente metáfora: "No quiero decir por esto, que aygan de corromperle por medios ilicitos, y reprobados; sino q obligados dentro de los terminos de lo licito, y honesto, los tengan los litigantes inclinados a su favor, asi como a el hechicero se le puede pedir lícitamente, que remueva el hechizo, que tuviere hecho, sin pedirle que use del arte, y pactos q tuviere con el Demonio, que si el alla se valiese de esto, no le ha de ser imputable a el que le pidio una cosa honesta, y buena: en el mismo modo se debera tratar a el Escribano...". (sic)

Regla Decimaquinta: "Nunca descomponerse, ni quejarse por las determinaciones poco favorables que se dieren en la causa, antes llevarlas con un genero de tolerancia y sufrimiento, que se equivoquen con la complacencia". "Es la paciencia tan semejante a la fortaleza, que parece nacida de ella, o nacida con ella: y por eso hubo quien la llamase Gemelas, $y$ alli abroquelandose con este escudo, podrá el litigante hacer sufrible el dolor de las determinaciones contrarias". Previene también el autor a no quejarse sólo por amor propio, pues: "Es abrir la puerta a las ofenzas con la quexa, y en vez de servir de remedio, 
y de consuelo, se añaden nuevos motivos para agrabios". Reconoce a su vez, con San Francisco de Sales, que hay un ideal en la conservación de la paciencia en los litigios, visto que: “... quien tiene moderación en medio de los procesos, tiene hecho el proceso de su canonización". (sic)

Regla Decimasexta: "Por último deverán observar los litigantes como regla la mas importante para correr con felicidad en los negocios el no emprehenderlos, ni seguirlos por tema", dado que en esto reside ordinariamente: "... la fuente de todas las desventuras. Un obstinado capricho contra la faltriquera, contra la quietud, y sosiego del litigante, contra sus conveniencias, y las mas de las veces contra su credito, no puede producir utilidad alguna". (sic)

Finaliza la primera parte con una reiteración del consejo principal a los señores litigantes: "Nunca se repite con demacia, lo que con exactitud debe ser observado. Quantas reglas contiene este papel, todas se dirigen a el mejor logro de las causas: pero en todo caso lo que mas importa a sus interesados, es abstenerse de pleitos, y solicitar antes de su ingreso, con verdadera eficacia su composición". (sic)

En este principal y reiterado consejo se concibe ya una anticipación histórica al actual paradigma desjudicializador de los conflictos, o más bien una reiteración indiana de aquel principio estoico, nunca rebatido, según el cual la mayor sabiduría consiste en vivir apartado de los pleitos. Y he aquí también reavivado el humanismo, en la obra olvidada de un sabio que vivió y trabajó en un medio premoderno, cultivando la singular virtud de dar a conocer a propios y profanos, generosamente, entre el esplendor y el humor, el arte de la jurisprudencia.

\section{Referencias}

Contreras, C. A. (2004, 4 de sept.). Orígenes del Colegio Tridentino en Comayagua. Diario Tiempo, San Pedro Sula, Honduras.

Honores, R. (s.f.). El uso de las probanzas de testigos en los litigios sobre curacazgos ante la Real Audiencia de Lima, 1550-1610. Recuperado de http:// www.alertanet.org/F2b-RHonores-pe.htm

Luján, J. (1981, 6 de nov.). Revista Historia Crítica, UNAH, 1(6).

Monjarrez, L. (1998). Introducción al estudio del derecho: primer curso. Managua: Unan de Managua, Bitecsa. 
Derecho y Realidad

Morse, R. M. (1999). El espejo de Próspero: un estudio de la dialéctica del nuevo mundo. México: Siglo Veintiuno.

Oquelí, R. (2004). Valle, entre la fantasía y el rigor. Choluteca: Subirana. 